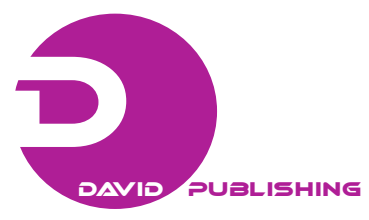

\title{
Analysis of Urban Morphology in Core Towns' Neighborhoods of Mexico: Santa Barbara's Neighborhood as a Case Study
}

\author{
Alaidé Retana-Olvera ${ }^{1}$, César Angel Peña-Salmón ${ }^{1}$ and Luz Maria Ortega-Villa ${ }^{2}$ \\ 1. Faculty of Architecture and Design, Autonomous University of Baja California, Mexicali B.C. 21240, Mexico \\ 2. Faculty of Human Sciences, Autonomous University of Baja California, Mexicali B.C. 21240, Mexico
}

\begin{abstract}
Cities' urban morphology is the result of historic, cultural, political and social processes. The historical cores in Mexican cities have high cultural diversity, which also intermingle pre-Hispanic cultures with colonial forms, as well with modernity and post-modernity irruption. The case study is Santa Barbara's neighborhood in Toluca City, which was founded in 1524, and the case study was the first neighborhood in Toluca's historical core. At present time, this neighborhood is considered as one of the most dangerous places in the city's historical core, therefore, it has been abandoned. This paper will display the changes in urban morphology of the neighborhood through the years from 1877 to 2010. For site evaluation, the methodologies of Ashihara (1982) and Lynch's (1961) were used in order to analyze positive and negative spaces, as well as main street visual features, street and avenue directions, street circulation and street circulation path configuration. The results show that the focal nodes are a key factor for economic and social reactivation, with which, through urban activation of vacant lots and the traditional use of the streets as public space, is possible to generate centripetal development to restructure the neighborhood.
\end{abstract}

Key words: Mexican neighborhood, urban morphology, urban process, suburbanization, dangerous spaces.

\section{Introduction}

The case study is Santa Barbara's neighborhood in Toluca. This city is located in the center of Mexico (Fig. 1). During pre-Hispanic time, it was called Toluca or Toluca Village, it has influences of Teotihuacan, Toltec, Chichimec and Mexica cultures [1], subsequently, it was influenced by Spanish culture during colonization. In 1524, Spanish evangelization started in Mexico and it is thought that Toluca was founded as a city by Spanish missionaries on March 19th of 1522. However, it was not officially considered as a city until September 12 th of 1799 when Charles IV signed the royal charter that gave it such category [2].

Toluca is bounded by Tolotzin, Coporo, Apinahuzco and Zopilocalco Hills [3], having the case study located

Corresponding author: Alaidé Retana-Olvera, Ph.D. candidate, research fields: sustainability, urban planning and urban-sustainable design. E-mail: alai.retol@gmail.com. in the Coporo Hill. Santa Barbara's neighborhood was the first neighborhood in Toluca's historical core [4]. In the present time, this neighborhood is considered as one of the most dangerous places in the city's historical core. This situation is linked largely to the urban morphology.

Currently, Toluca City has a total of 2,480 million inhabitants [5], however, unlike the rest of the city and municipality, the rate of population growth in the last 10 years is negative (Fig. 2), and the largest decrease was presented in the 2000-2005 period [6], with the decrease of $16.5 \%$ of the total population, slowing down in the next period 2005-2010, with $1.7 \%$ of population decrease. This indicates that the neighborhood is driving population out and, therefore, decreasing its density.

The objective of the analysis is to propose a viable path to solve the problem of abandoned historic cores in Mexico, based on historical study of urban morphology of case study. 


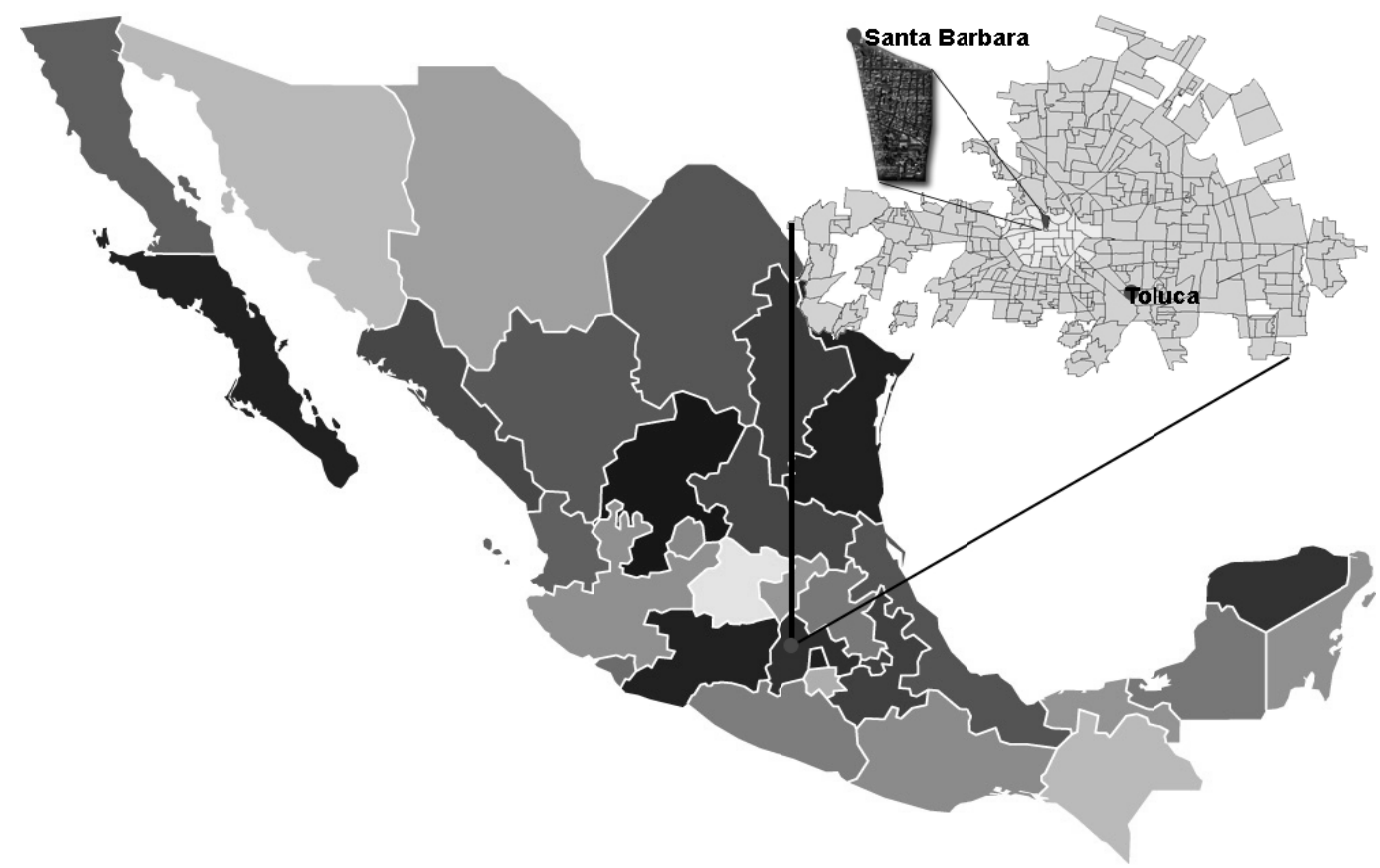

Fig. 1 Santa Barbara's neighborhood location.

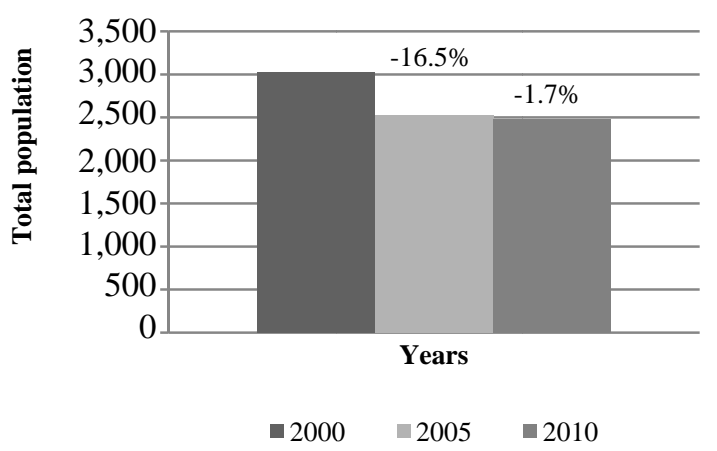

Fig. 2 Rate of population growth in the district of Santa Barbara (2000-2010).

Source: based on census 2000, 2005 and 2010 from the National Institute of Statistics and Geography.

\section{Methodology}

The methodology used is comprised of four stages and integrated the analysis methods of Ashihara [7] and Lynch's [8]: (1) the analysis of positive and negative space proposed by Ashihara [7]; (2) the study of the importance of public space in the community life of the local people; (3) connectivity; (4) the most important main visuals in the neighborhood.

In the first phase, the first part shows the analysis proposed by Ashihara [7], which shows the centripetal and centrifugal development in the case study and the landmarks that cause centripetal development.

The second phase, which is named from "urban space to community life", consisted in showing the importance of public space for the residents of the neighborhood, considering that, in the case study, there are not such spaces, so people use other spaces, also showing the importance of the street as historical space of social living.

The third stage consisted in the form of connectivity that exists in the neighborhood, for what was considered in the theory of Kevin Lynch. It shows the importance of focal nodes in social and economic life of the neighborhood.

The fourth consisted in the analysis of the main visuals, and their direct relationship with the history and the city.

\section{Positive and Negative Space}

The outdoor space, according to Ashihara [7], is created to define the nature of a frame in two spatial planes, in difference with the indoor space which is defined by three spatial planes, when "the outdoor space develops within itself, a centripetal order 
constitutes a positive space" [7] and if, by nature, the space is centrifugal, it becomes a negative space. The area that is created within centripetal frame is full of meaning as it holds human functions and purposes. When Ashihara [7] mentions the negative and positive space, referring not only in the roll that plays the space inside and outside of the architecture, but also the intent with which they are designed. In other words, when an outdoor area is designed in conjunction with the function of the building, this space is positive, whereas if it is designed without human intention, it is perceived as negative.

In the following images, we can appreciate Ashihara's first view about space, in the negative, which is constituted by the building's frame and positive by the building's core (Figs. 3 and 4).

Fig. 5 shows the current urban constitution of the neighborhood, in which two zones are distinguished with centripetal development and, therefore, positive (E, I) and four with development dispersed, therefore, negative (D, H, F and $G$ ).

The main characteristic of those with a positive development is that they are religious congregations ( $\mathrm{E}$ is the Church of Santa Barbara and I is the Temple of Carmen). We can also find No. 1 High School and the Museum of Fine Arts (in I). That is to say, they are meeting centers, in which the public and natural space have an important role which was planned and, according to Ashihara, has meaning, functions and human purposes that makes it a positive space.

In the early nineteenth century, as shown in Figs. 3 and 4, dominated by the negative space, the neighborhood's inner order was completely centrifugal, even though Carmen Temple (A) had already existed, constructed in 1698, and, being a religious institution, it could have created centripetal development towards itself, as we can see in Fig. 4, in which the Church of Santa Barbara ${ }^{1}$ (C) begins to give the feeling of being a center from which there is a centripetal development,

\footnotetext{
${ }^{1}$ Before the Church of Santa Barbara, chapel existed with the same name, which was built between the sixteenth and seventeenth centuries, today highly impaired [9]
}

as well as the current street Pedro Cortez (B), which is a guiding principle in the neighborhood, giving the feeling that the space is actually positive.

As opposite, spaces, identified as D, F, G and H, have a centrifugal development and, therefore, negative. In the case of $\mathrm{D}, \mathrm{F}$ and $\mathrm{G}$, they are characterized for a large amount of natural area, and considering what Ashihara says, these spaces have been poorly planned. In addition to $\mathrm{H}$, there isn't any

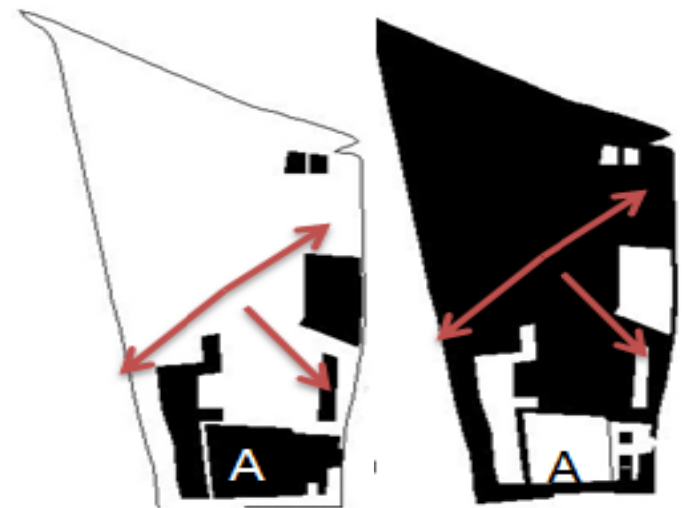

Fig. 3 Positive and negative space in Santa Barbara's neighborhood, 1834.

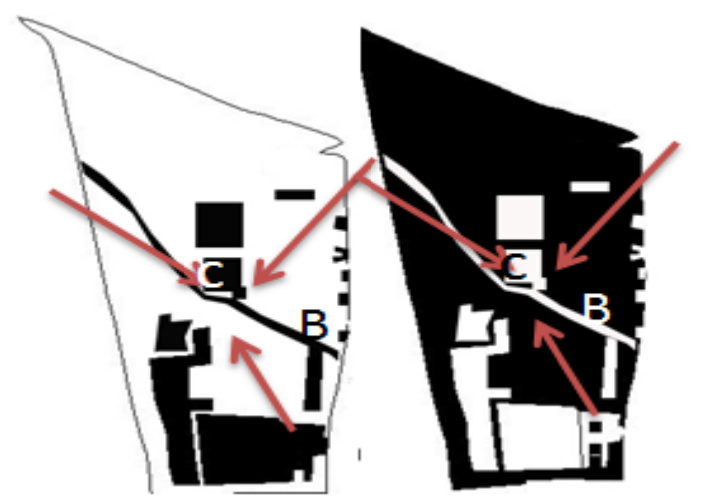

Fig. 4 Positive and negative space in Santa Barbara's neighborhood, 1877.
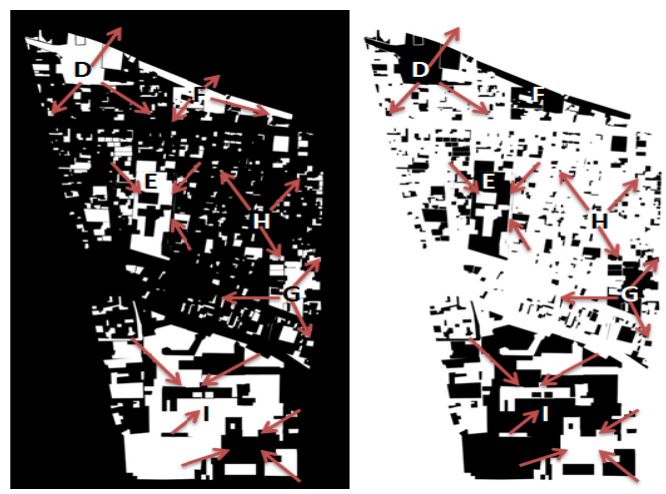

Fig. 5 Positive and negative space, 2012. 
natural space available, and there is not a meeting center causing a positive development in that area. In all cases, there is a lack of meaning in the natural space, i.e., no functions or human purposes.

\section{From the Urban Space to Community Life}

Rabotnikof [9] said that public space can be viewed in three ways: from the perspective of recovery, or the assumption of a loss of tone and classic image of the public sphere in a heterogeneous society like ours. The author proposes three paths to choose considering the following: installed in nostalgia by the place lost, report the different processes of privatization, or accept the challenge of thinking about new forms of articulation between public and private in the various spheres of social life [9].

The third way you can take is to revitalize public life of the neighborhood. In the same way, Sato mentioned that you have to consider that "there are private use public properties and private properties for public use, with all the historical and social intermediate joints" [10].

In the neighborhood, the social behaviors mentioned by Sato [10] are presented, social meeting points are not typical public space such as parks, squares and gardens, but are the church atriums which make public space function (Fig. 6, yellow).

Santa Barbara does not have any public space inside, but near it there are other spaces that assume this role, as the esplanade of the Cosmovitral (botanical garden) and Spain Plaza (Fig. 6, numbers 1 and 2, respectively), also the parking lot of Teatro Morelos and public buildings esplanades, which are spaces that are used and under-used throughout the day to do various public and private activities. The under-utilization of open spaces and the use of public spaces outside the neighborhood show that the community requires this kind of infrastructure, in which no sport activities can be performed.

If we consider what Sato and Rabotnikof have said, green areas that exist in neighborhood schools (Fig. 6,

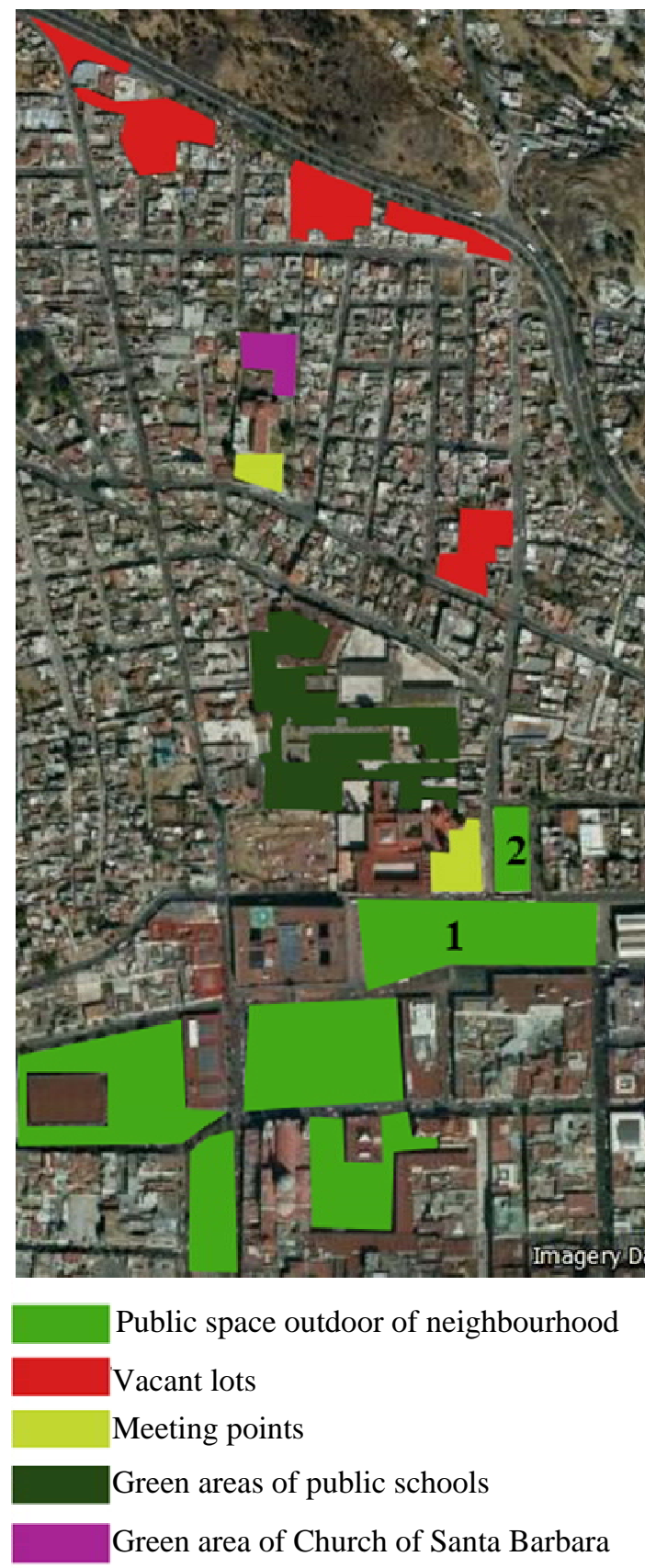

Fig. 6 Social meeting spaces and vacant lots.

army green) may have dual function for the ones that they were intended: during the morning when students are in the facilities, and during the afternoon when they are opened to the public.

As a traditional neighborhood space, we find the streets whose main function goes back to the 19th century. In Figs. 7 and 8, we show that market was installed in the late 19th century, which used to occupy 


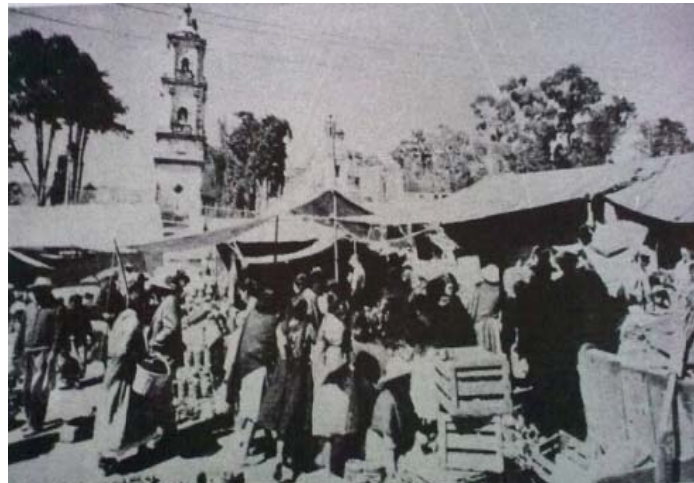

Fig. 7 Market opposite the Temple del Carmen, seen from the esplanade.

Source: Naime, El ayer de Toluca, 1991 [11].

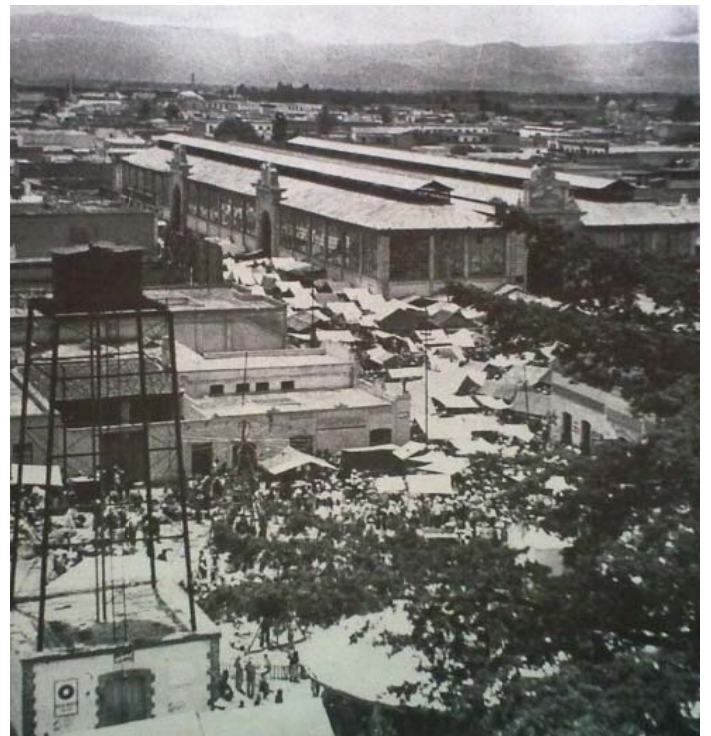

Fig. 8 Market opposite the Temple del Carmen, seen from the bell tower.

Source: yesterday in Toluca, 1991 [11].

a great portion of Benito Juarez North and Santos Degollado Street at the time the Spain Plaza did not exist yet, and Cosmovitral was a market, not the botanical garden that it is nowadays.

Benito Juarez Nte. Street is not used as a market anymore, but it still has a great social activity, especially when school classes are over and when local festivity of Our Lady of Carmen (very frequent activity in Mexican Culture) (Fig. 9) takes place. During this festivity, the street is completely closed and also, Plaza Spain is used for the same purpose. However, this traditional fair is about to disappear due to the traffic disturbances it causes.

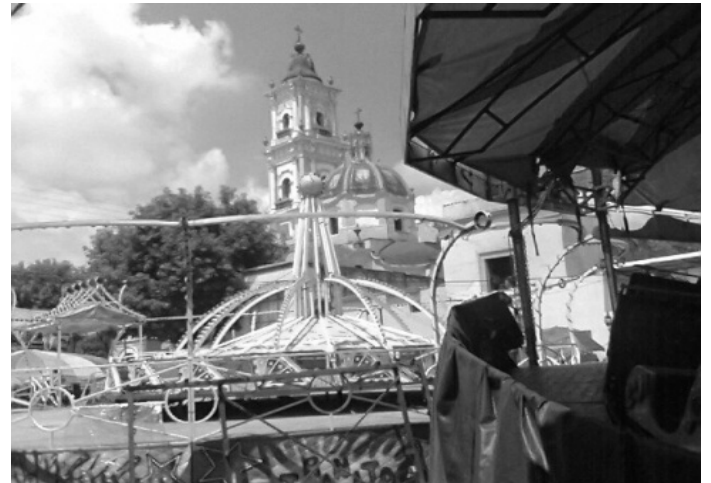

Fig. 9 Carmen Temple fair.

Source: http://felzm.deviantart.com.

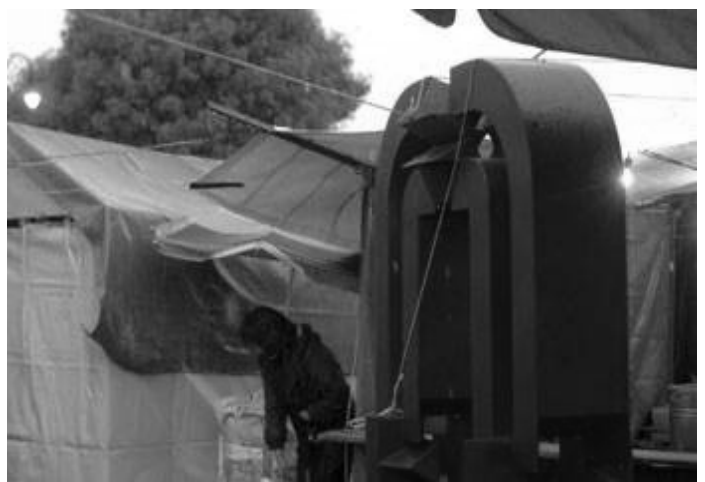

Fig. 10 Chaos caused by fair of Carmen.

Source: http://www.oem.com.mx.

Traffic disturbance occurred the day before, when street markets established by themselves with or without authorization, Spain Plaza located besides the Temple of Carmen. Even the newly opened sculpture of artist "Sebastian" (Fig. 10) was used to place their roofs [12].

In the same article, it is mentioned that the fair increases crime rates in the neighborhood, but it is a tradition, which used both the temple atrium, Plaza Spain and the street.

This social interaction space is important for the population of the neighborhood. Their traditions and folk reflect this, but they do not have the necessary space, either public or public-private space, which would allow them to perform these activities freely.

\section{Connectivity}

In his paper "The Pattern of the Metropolis” (1961), Lynch establishes the basis for urban connectivity, he says that connectivity is the spatial pattern of a city 
which is made by the location of the different activities, as well as circulation patterns and structure of the city. In 2010, Duany et al. [13] defined the connectivity as the relationship between the neighborhoods in order to avoid inefficient hierarchical model of urban sprawl, which used the same collect avenues, besides that all compatible land uses should be connected.

Connectivity is given from the location of services and equipment in the network avenues, primary, secondary, tertiary, walkways and alleys through which the local and external people are transported (Fig. 11) through which different people perform daily activities.

In 1961, Lynch categorized what he called "the three vital factors" 2 with which you can adjust the shape of the metropolis to specific patterns of these three main characteristics which are derived for each pattern: grain (Fig. 12), the focal organization (Fig. 13) and accessibility (Fig. 14).

The grain is the ratio of the area occupied by the buildings on the ground to the rest of the area, i.e., the texture that buildings space shapes in urban land way [14].

Lynch [8] represented in schematical forms the possibilities that may be of texture in the urban space, one that locates at the top right of the Fig. 12, which is a fine grain (as the author defines it) as there are few empty spaces between buildings, and the other is a coarse grain in which there is greater spacing between elements constructed.

In the neighborhood, you can find both kinds of texture. In the northern area, there is a lot of constructed space, meanwhile in the southern area, the non-constructed space is dominant.

The interrelationship of the concentration nodes is what Lynch [8] defines as focal organization. In the neighborhood, there are three main concentration

${ }^{2}(1)$ Density and structural condition, provided the rates of physical resources, are an urban region; (2) capacity, type and pattern of traffic conditions, for the communication and circulation, may constitute the most essential function of a city; (3) spatial pattern, the location of the diverse activities, which create patterns of movement and physical structure. nodes (Fig. 13): the Church of Santa Barbara (1), Secondary School (2) and the Temple of Carmen (3). Two secondary avenues and local avenues link them. These nodes and the way in which they are communicated, generate a path of nodes that define the neighborhood.

Lynch [8] defined the accessibility as the proximity in time to all points of a region to a particular activity or service. In his proposal, Lynch [8] adds accessibility scheme, i.e., it is not only time, but also the way in which different services communicate with each other. Fig. 12 displays this scheme. It shows the services (white circles) and nodes (black circles) are concentrated on a large amount of streets and avenues that distribute to the population to other services. In the neighborhood, seven main nodes (Fig. 14, little circles) are located, which are where most pedestrian avenues converge to access most of the services available in the neighborhood. These nodes are located only in secondary avenues.

Having mentioned all the three elements, Lynch [8] distinguishes five urban patterns: scattered plot, settlements shaped galaxy, central city, urban star and ring. From these patterns, galaxy (Fig. 15) has the highest correlation with the area of study because development is available. The development is in small units, each with a density peak and separated from one another by a zone of zero or low structural density (Fig. 12). Similarly, the activities are concentrated in densities peaks, which, concerning the neighborhood, are arranged in a line. Lynch [8] mentions that the advantages of this pattern are comfort, independence and stability. In addition, it also improves communication and it is easier to improve the local image, and has a wider range of choices than only dispersion. The author also mentions that even if there is a variety of activities or activity centers, the time-distance factor is not necessarily low, and in order to achieve that, this factor would have to decrease, and we would have to persuade people to work and shop inside the same center in which they are located. In the 
Analysis of Urban Morphology in Core Towns' Neighborhoods of Mexico: Santa Barbara's Neighborhood as a Case Study

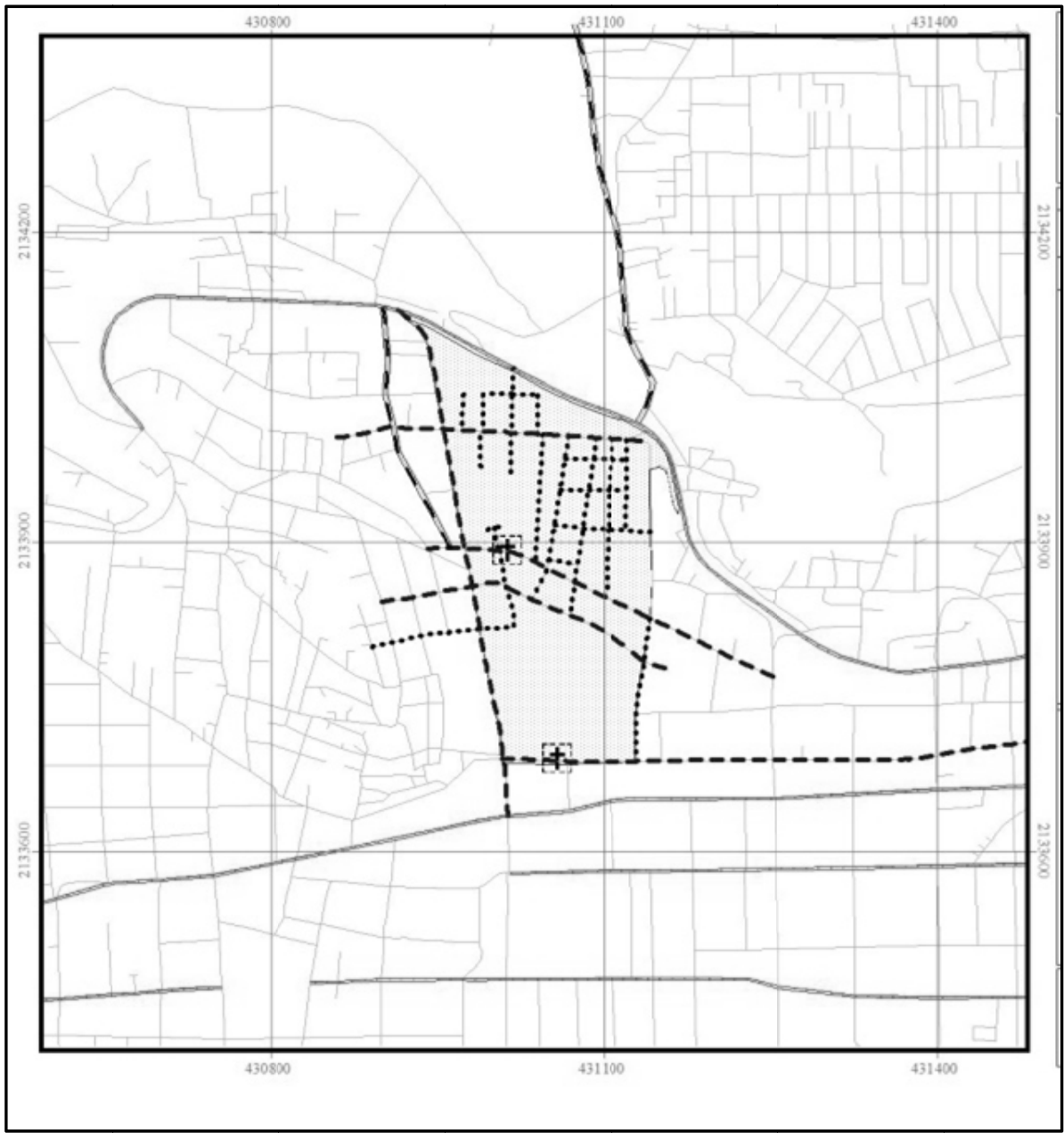

Fig. 11 Avenues primary, secondary and local Santa Barbara's neighborhood area.

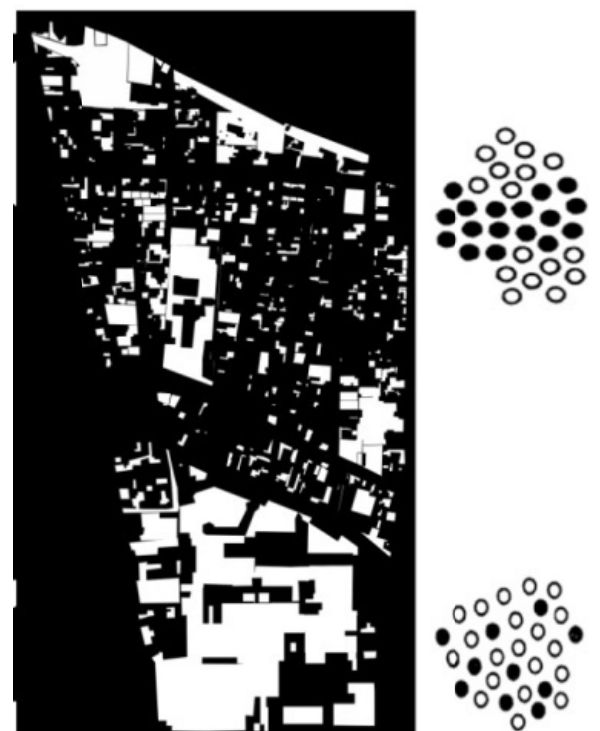

Fig. 12 Grain of Santa Bárbara's naighborhood (seen in negative).

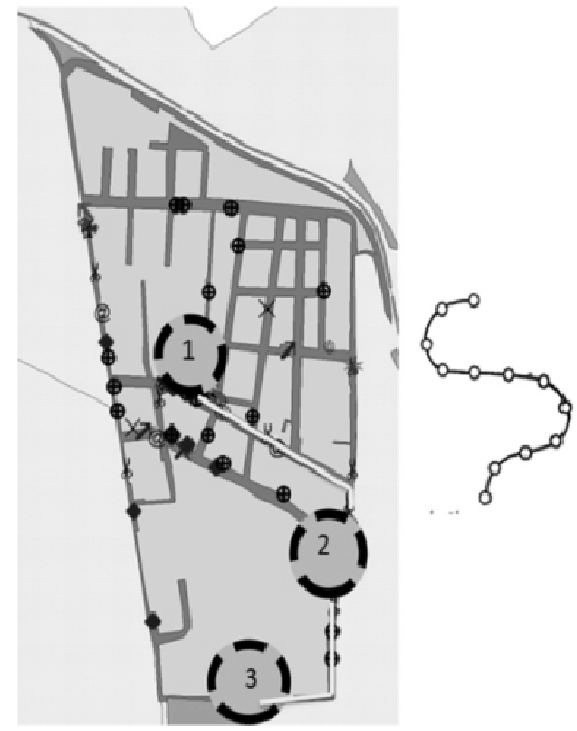

Fig. 13 Focal organization. 


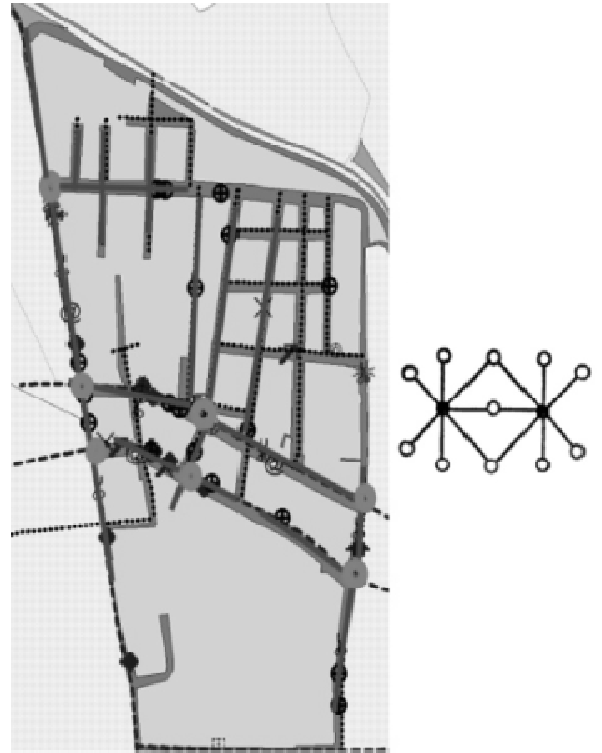

Fig. 14 Accessibility.

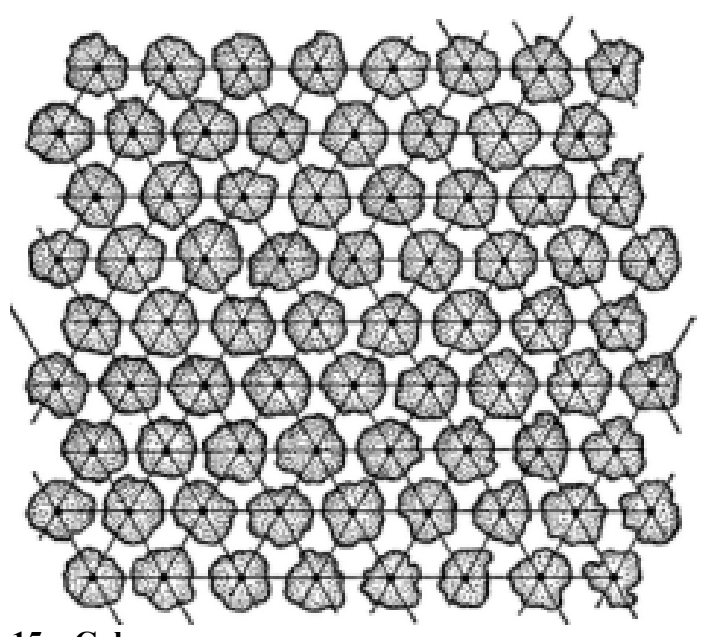

Fig. 15 Galaxy.

Source: Lynch, "The pattern of the metropolis" [8].

case of the study area, there is a high diversity of services, people have a high intensity of shopping areas within the same neighborhood, hence, the time-distance factor diminishes.

In the neighborhood, there are three focal points. And near Points 1 and 2 (Fig. 13), there are six access nodes (Fig. 14), which are located along two secondary avenues, and along one of these, crosses a transit line, while Node 3 is where there is an access to the neighborhood, these nodes and focal points are developed in Pedro Cortez Street to the south, but in the north, there are not.

Lynch [8] argues that core towns should be in a balance of composition, which does not occur within the neighborhood where the north is lacking in accessibility, and services both in quantity and diversity diminish in comparison to the rest of the neighborhood, even though the grain is high in this area, there is no a focal node and there are a lot of vacant lots.

\section{Analysis of the Main Visual (Landmarks)}

Of the three focal nodes, the temples are which cause the most visual impact, however, they are not part of the landmarks inside the neighborhood because of their location and the configuration of the streets. The Temple of Carmen has been important in this regard, for its location in the historic core town. Although the configuration of the streets has been changed (Fig. 16), it continues to have visual impact (Fig. 17).

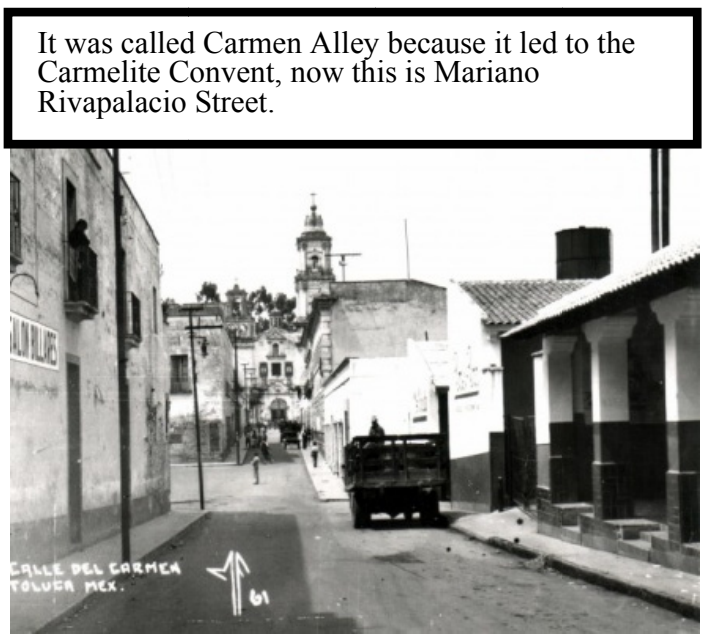

Fig. 16 Alley of Carmen, late 19th century.

Source: http://www.skyscrapercity.com.

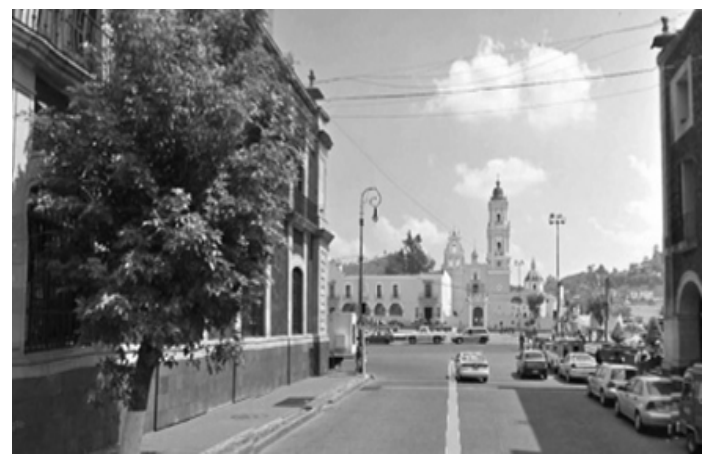

Fig. 17 View of Temple of Carmen, today. 


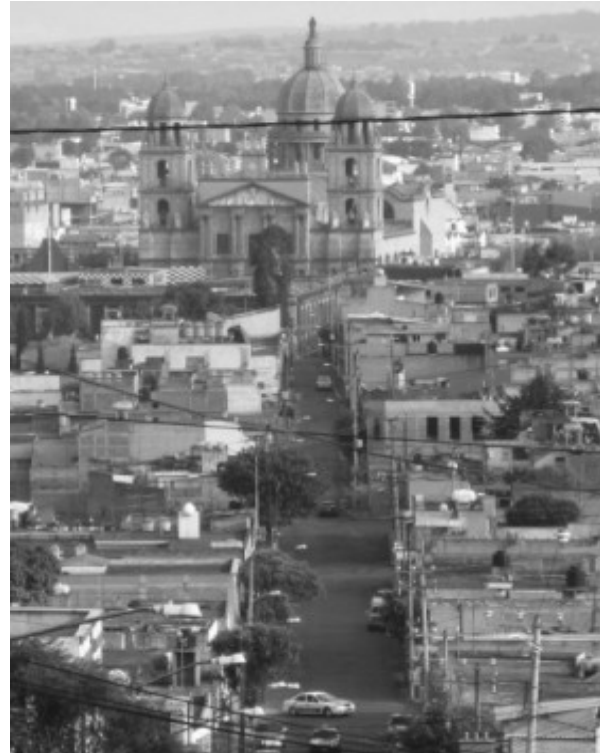

Fig. 18 View towards the cathedral, today.

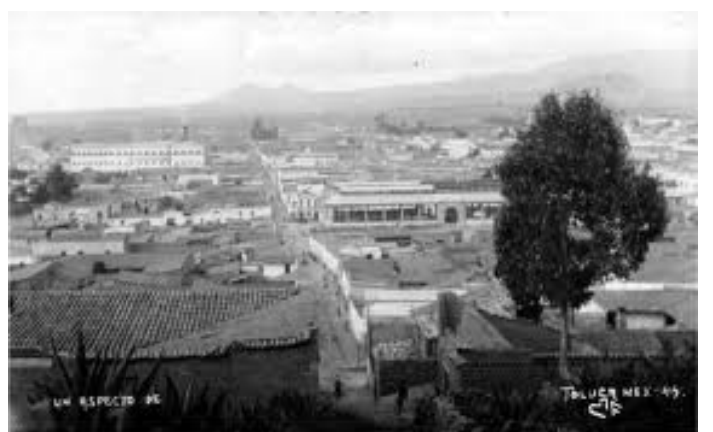

Fig. 19 View of the neighborhood to the City of Toluca, late 19th century.

Source: Naime, El ayer de Toluca [11].

Another landmark of the neighborhood, although it is not within it, is the cathedral, located in the core of the historic center. Fig. 18 shows the Cathedral view from the north of the neighborhood, both the temple and the historical center viewed from the north of the district. Fig. 19 shows the view of the city from the late 19th century, taken from the Tollocan Ave. (the northern edge of the neighborhood).

\section{Conclusions}

In accordance with Ashihara [7], we identified that there are areas in the neighborhood of both centrifugal and centripetal development. Ideally according to the author, the centripetal development should be predominant, as this involves a human intentionality in the better design and urban development, but in reality, this does not occur. Fig. 20 shows the current status of the neighborhood and a possible way to achieve a centripetal development.

It has been mentioned that the northern zone of neighborhood is the most conflicting area, which coincides with predominant centrifugal development. Moreover in this area, there are a lot of vacant lots, which currently create more chaos, visual and ground pollution.

The strategy to solve this problem may be generating focal nodes in vacant lands to create safe areas of social life, with infill development, taking advantage of visual shots inside the neighborhood (Fig. 21).

It is characteristic of historic core towns in Mexico to have a central square that develops community life, and also sticks together with the urban structure. In the

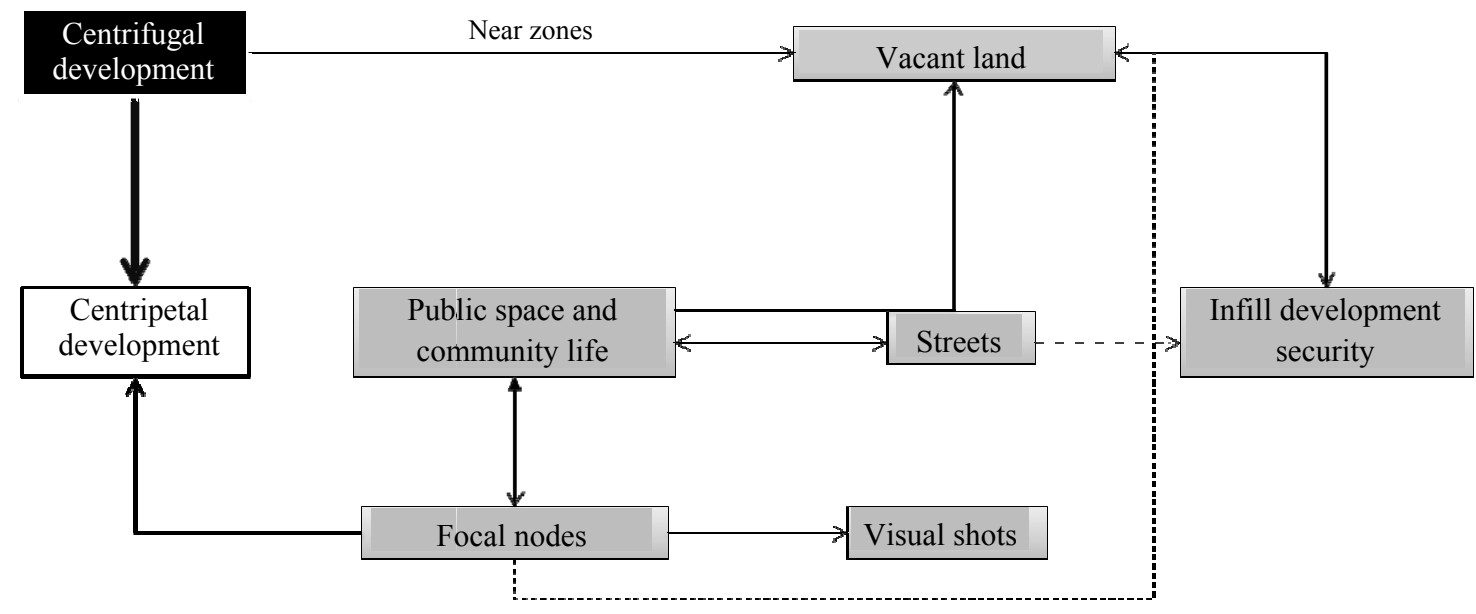

Fig. 20 Analysis of the urban morphology's neighborhood. 


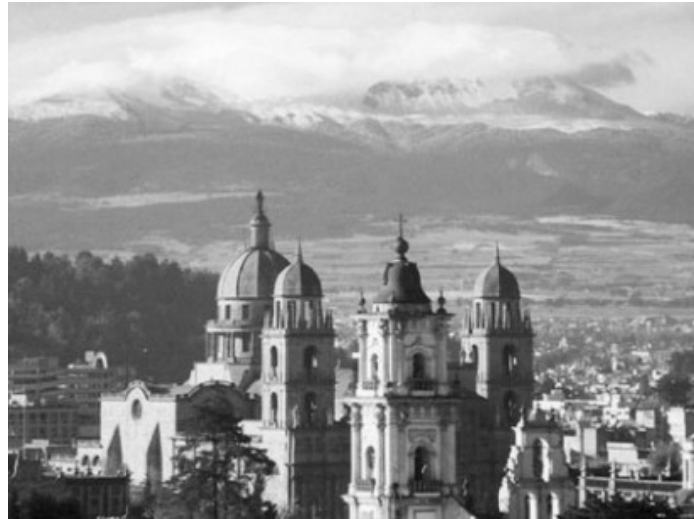

Fig. 21 View of Carmen Temple, the cathedral and the Volcano of Toluca.

case study, this space does not exist. It has been identified that there are available area for its development, which would bring social, economic and cultural history within this space.

\section{References}

[1] R. Hernández, El Valle de Toluca. Época prehispánica y siglo XVI, El Colegio Mexiquense (The Valley of Toluca. Prehispanic and Sixteenth Century), A.C., Zinacantepec, 2009. (in Spanish)

[2] Goverment of Estate of Mexico, Enciclopedia de los Municipios y Delegaciones del Estado de México (Encyclopedia of the Municipalities and Delegations of the State of Mexico) [Online], http:/e-local.gob.mx/work/templates/enciclo/EMM15me xico/municipios/15106a.html (accessed Apr. 23, 2012). (in Spanish)

[3] G. Gallardo, L. Osornio, Los archivos parroquiales de la Villa de Toluca (The parish records of the town of
Toluca), 1684-1760, Papeles de Población (Papers of Population) 15 (60) (2009) 215-243. (in Spanish)

[4] Diócesis de Toluca. Zonas Pastorales (Diocese of Toluca. Pastoral Areas) [Online], http://www.diocesistoluca.org. mx/new_ver1_0/lug/lugares.html (accessed Mar. 12, 2012). (in Spanish)

[5] Population and Dweling Census, INEGI (National Institute of Statistics and Geography), Mexico, 2010.

[6] Population and Dweling Census, INEGI, Mexico, 2000.

[7] Y. Ashihara, El diseño de Espacios Exteriores (The Design of Outdoor Spaces), Gustavo Gili, Barcelona, 1982. (in Spanish)

[8] K. Lynch, The pattern of the metropolis, Daedalus 90 (1) (1961) 79-98.

[9] N. Rabotnikof, Introducción: Pensar lo Público Desde la Ciudad (Introduction: Thinking the Public from the City), in: K. P. Ramírez, Espacio público y reconstrucción de la ciudadanía (in: K.P. Ramirez, Public Space and Reconstruction of Citizenship), Porrúa, México, 2003, pp. 17-24. (in Spanish)

[10] A. Sato, Lo Público del Espacio (The Public Space) [Online], 2012, http://www.scielo.cl/scielo.php?pid= S0717-69962012000200003\&script=sci_arttext (accessed July 15, 2012). (in Spanish)

[11] A. Naime, El ayer de Toluca, Gobierno del Estado de México (Yesterday in Toluca), Mexico State Government Toluca, 1991. (in Spanish)

[12] El Sol de Toluca (Newspaper) (2012-15-July), Caos por la feria del Carmen (Chaos by Carmen Fair) [Online], http://www.oem.com.mx/elsoldetoluca/notas/n2618544.html (accessed July 15, 2012). (in Spanish)

[13] A. Duany, E. Plater-Zyberk, J. Speck, Suburban Nation, North Point Press, New York, 2010

[14] Population and Dweling Census, INEGI, Mexico, 2005. 